\title{
Studies on In Vivo Formation of Nitroso Compounds (VIII)
}

\author{
In Vitro and In Vivo Formation of Dimethylnitrosamine \\ by the Mixing of Different Kinds of Foods
}

(Received April 28, 1976)

Hajimu Ishiwata

(National Institute of Hygienic Sciences: 18-1, Kamiyoga 1-chome, Setagaya-ku, Tokyo)

\begin{abstract}
Remarkable amounts of nitrite were formed in the juice of komatsuna, rape "Komatsuna", after incubation at $30^{\circ} \mathrm{C}$ for $24 \mathrm{hr}$. When the mixtures composed of the above incubated komatsuna juice, marine products and simulated gastric juice were incubated at $37^{\circ} \mathrm{C}$ for $1 \mathrm{hr}, 5.6 \sim 25.9 \mu \mathrm{g}$ of dimethylnitrosamine (DMNA) was formed. Furthermore, 0.12 $0.53 \mu \mathrm{g}$ of DMNA was detected in the stomach contents of guinea-pigs which were administered with the incubated komatsuna juice and salted guts of cuttlefish, "ika-shiokara". In the control groups of the animal experiment, which were administered with incubated komatsuna juice and water, ika-shiokara and water, or fresh komatsuna juice and ikashiokara, DMNA was not detected.
\end{abstract}

\section{Introduction}

The nitroso compounds, a group of potent carcinogens which produce tumors in laboratory animals, ${ }^{1)}$ are formed by the reaction of nitrite with secondary amines under an acidic condition. An exposure of these carcinogens to man may occure in the following two ways: a) ingestion of nitroso compounds existing in life environments, especially in various foods; ${ }^{2) \sim 4)}$ b) in vivo formation of nitroso compounds from nitrite and secondary amines under an appropriate condition such as in stomach. ${ }^{\text {() }}$ 7) Moreover, nitrate is also utilized as a source of nitrite, because it is easily converted to nitrite by various microorganisms. ${ }^{7) \sim 9 \text { ) }}$

Nitrite and nitrate are widely distributed in natural products ${ }^{10), 11)}$ such as vegetables and cereals, and sodium nitrite is also used as a color fixative in meat products or fish roes. Secondary amines, especially dimethylamine (DMA) which is another precursor of dimethylnitrosamine (DMNA), are widely detected in seafoods. Kawamura, et al. ${ }^{12)}$ and Ito, et al. ${ }^{13)}$ determined the amount of DMA in raw or roasted fishes and many other foods.
However, all the experiments concerning in vitro or in vivo formation of nitroso compounds were carried out by using pure compounds such as sodium nitrite, sodium nitrate and secondary amines, but not ordinary foods containing these compounds, such as vegetables and fishes.

The present study was designed to demonstrate the in vitro and in vivo formation of DMNA by using komatsuna, rape "Komatsuna", and a few kind of seafoods.

\section{Experimental methods}

\subsection{Foods}

Komatsuna, salted cod roes (tarako), dried codfish (hidara), salted guts of cuttlefish (ikashiokara), dried cuttlefish (surume) and flaked dried-bonito (katsuo-kezuribushi) were used.

The contents of nitrite, nitrate, DMA and DMNA in these foods are shown in Table 1.

\subsection{Incubation of komatsuna juice}

A juice of komatsuna was prepared by a juicer. When the komatsuna juice was incubated at $30^{\circ} \mathrm{C}$ for $24 \mathrm{hr}, 815 \sim 3,337 \mathrm{ppm}$ of nitrite were formed, but no DMA and DMNA were detected. 
Table 1. Contents of Nitrite, Nitrate Dimethylamine and Dimethylnitrosamine in the Foods used (ppm)

\begin{tabular}{llccc}
\multicolumn{1}{c}{ Food } & Nitrite & Nitrate & DMA & DMNA \\
\hline Komatsuna juice*1 & N.D. & $4993 \sim 6165$ & N.D. & N.D. \\
Tarako*2 & N.D. & 1.6 & 112.5 & N.D. \\
Hidara*3 & N.D. & 3.2 & 154.5 & N.D. \\
Ika-shiokara*4 & N.D. & 2.9 & 187.5 & N.D. \\
Surume*5 & N.D. & 0.6 & 183.0 & N.D. \\
Katsuo-kezuribushi*6 & N.D. & 1.3 & 75.8 & N.D.
\end{tabular}

*1 juice of rape "Komatsuna" prepared by a juicer

*2 salted cod roes

*3 dried codfish

*4 salted guts of cuttlefish

*5 dried cuttlefish

*6 flaked dried-bonito

\subsection{Formation of DMNA in vitro}

Twenty milliliters of the above incubated komatsuna juice and $10 \mathrm{~g}$ of the homogenate of tarako or ika-shiokara or the powder of hidara, surume or katsuo-kezuribushi were added to $20 \mathrm{ml}$ of simulated gastric juice. ${ }^{14)}$ The mixture of which $\mathrm{pH}$ was about 5.0 was incubated at $37^{\circ} \mathrm{C}$ for $1 \mathrm{hr}$, and used as the sample solution for the determination of DMNA.

\subsection{Formation of DMNA in vivo}

Ten milliliters of the incubated komatsuna juice and $2.05 \mathrm{~g}(2 \mathrm{ml})$ of the homogenate of ika-shiokara were given simultaneously by a stomach tube to ginea-pigs (Hartley, female, body weight $600 \sim 800 \mathrm{~g}$ ) which have been fasted from the day before. The stomach was exenterated after $1 \mathrm{hr}$, and the contents were taken out. The stomach was washed out with a small amount of water, and the washings were combined to the contents. Clear supernatant was obtained by centrifugation ( $3000 \mathrm{rpm}, 10 \mathrm{~min})$, and the precipitates were washed with a small amount of water and centrifuged again. Both supernatants were combined and used as the sample solution for the determination of DMNA.

\subsection{Analytical procedures}

Nitrite, ${ }^{16)}$ nitrate $^{15)}$ and $\mathrm{DMNA}^{16)}$ were determined by the method described previously. DMA was determined by the method described by Ito, et $a l .{ }^{17), 18)}$

\section{Results}

\subsection{Formation of nitrite by incubation of} komatsuna juice

Time-course of nitrite formation during the
Table 2. In Vitro Formation of Dimethylnitrosamine by Mixing the Incubated Komatuna Juice with Marine Products

Marine product DMNA formed $(\mu \mathrm{g})$

$\begin{array}{lr}\text { Tarako } & 5.6 \\ \text { Hidara } & 11.5 \\ \text { Ika-shiokara } & 25.9 \\ \text { Surume } & 9.5 \\ \text { Katsuo-kezuribushi } & 8.0\end{array}$

Ten grams of marine products and $20 \mathrm{ml}$ of incubated komatsuna juice were added to $20 \mathrm{ml}$ of simulated gastric juice. The $\mathrm{pH}$ of the reaction mixtures was about 5.0.

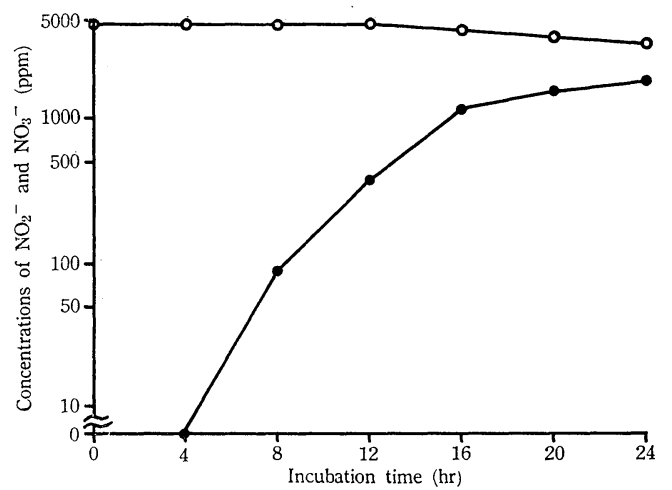

Fig. 1. Formation of nitrite by the incubation of komatsuna juice at $30^{\circ} \mathrm{C}$
○, Nitrite
$\bigcirc$, Nitrate

Formation of nitrite and consumption of nitrate were not observed during the incubation period of komatsuna juice treated with a membrane filter. 
incubation of komatsuna juice at $30^{\circ} \mathrm{C}$ was shown in Fig. 1. Fresh komatsuna juice contained more than $5000 \mathrm{ppm}$ of nitrate, but no nitrite. Approximately $100 \mathrm{ppm}$ of nitrite was formed after $8 \mathrm{hr}$, and the concentration was increased to $2,040 \mathrm{ppm}$ after $24 \mathrm{hr}$, accompanying the consumption of comparable amount of nitrate. When bacterial filtration of fresh komatsuna juice was carried out by using a membrane filter (pore size: $0.45 \mu$, Sartorius Co.,), no formation of nitrite was observed during the incubation period. This results showed that nitrite in the juice was formed by microorganisms originally existing in komatsuna, of which number was $3.3 \times 10^{6}$ cells $/ \mathrm{ml}$.

\subsection{In vitro formation of DMNA by mixing} of komatsuna juice with marine products

The komatsuna juice which was previously incubated at $30^{\circ} \mathrm{C}$ for $24 \mathrm{hr}$, as a source of nitrite, and tarako, hidara, ika-shiokara, surume or katsuo-kezuribushi, as a source of DMA, were incubated at $37^{\circ} \mathrm{C}$ for $1 \mathrm{hr}$ with simulated gastric juice. The amounts of DMNA produced in the incubation mixtures were shown in

Table 3. The Amount of Dimethylnitrosamine in the Stomach of Guinea-pig $1 \mathrm{hr}$ after Oral Administration of Incubated Komatsuna Juice and Ika-shiokara

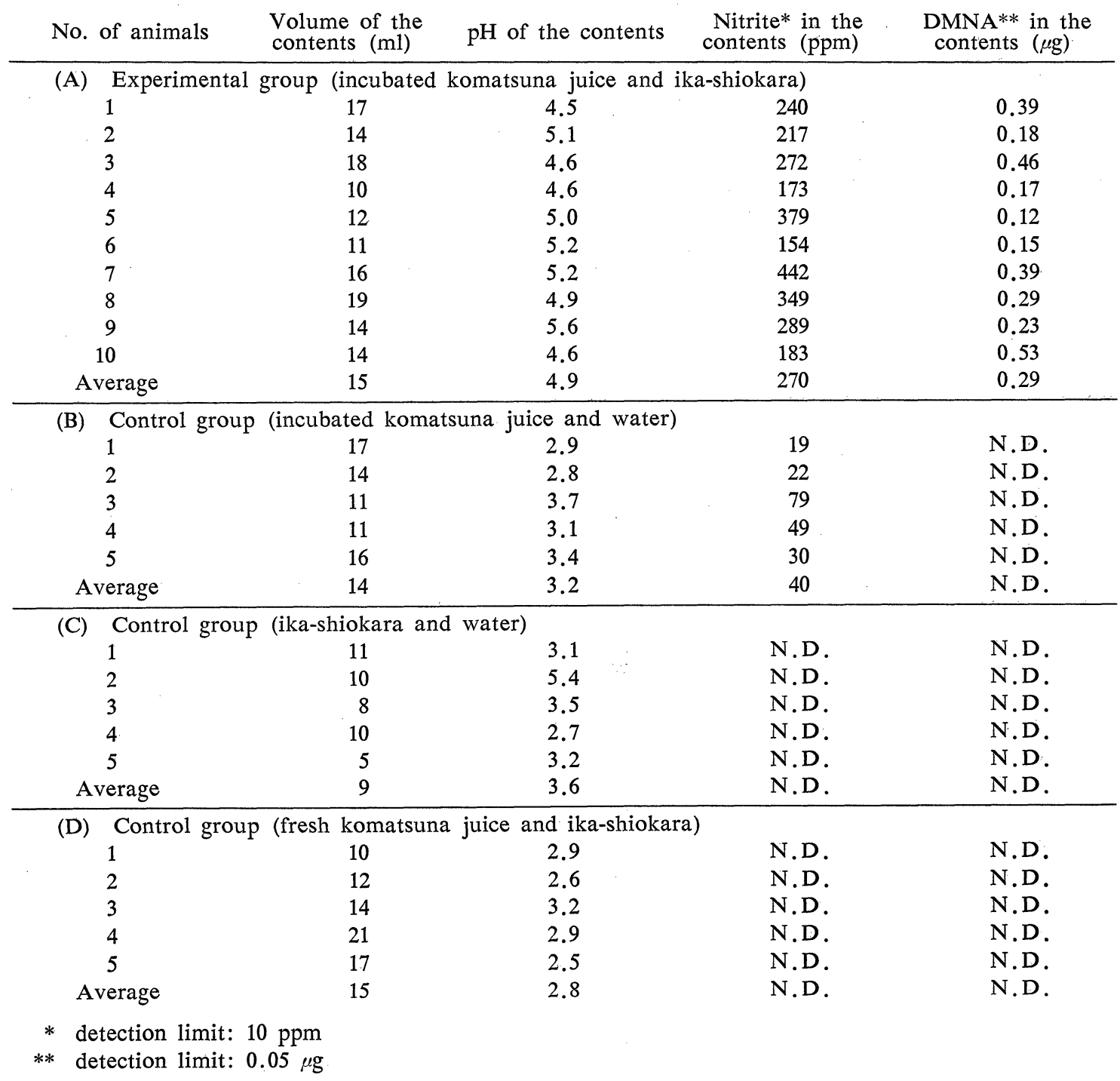


Table 2.

Significant amounts of DMNA were detected in all the incubation mixtures tested, and especially $25.9 \mu \mathrm{g}$ of DMNA was formed in the incubation mixture containing ika-shiokara. The $\mathrm{pH}$ of the incubation mixtures was about 5.0 and did not change during $1 \mathrm{hr}$-incubation. Since it was reported that the optimum $\mathrm{pH}$ of nitrosation of DMA was $3.3^{5)} \sim 3.4,,^{19)}$ the above $\mathrm{pH}$ was a little higher than the optimum value.

On the other hand, when fresh komatsuna juice was incubated with the marine products in the simulated gastric juice at $37^{\circ} \mathrm{C}$ for $1 \mathrm{hr}$, DMNA was not detected. DMNA was not also detected in the incubation mixture of incubated komatsuna juice and simulated gastric juice.

\subsection{Formation of DMNA in the stomach of guinea-pig}

DMNA was formed at the level of $0.12 \sim 0.53$ $\mu \mathrm{g} /$ animal in the stomach of guinea-pigs which were administered with incubated komatsuna juice and ika-shiokara (Table 3-A). The $\mathrm{pH}$ of the stomach contents ( $\mathrm{pH}$ 4.9) was almost the same as that of the in vitro experiment. In each control group which was administered with incubated komatsuna juice and water (Table 3-B), ika-shiokara and water (Table 3-C), or fresh komatsuna juice and ika-shiokara (Table 3-D), DMNA was not detected, but the $\mathrm{pH}$ of the stomach contents ( $\mathrm{pH} 2.8 \sim 3.6$ ) was more acidic than the former ( $\mathrm{pH} 4.9)$. Although the amount of DMNA formed was lower than in the case of the in vitro experiments, these results coincided with those of in vitro formation of DMNA.

\section{Discussion}

In the previous paper, ${ }^{20)}$ the present author reported that more than $500 \mathrm{ppm}$ of nitrite was formed by the incubation of some vegetable juices with natto at $37^{\circ} \mathrm{C}$ for several hours, and pointed out that it was mainly formed by the action of Bacillus natto in natto.

In the present paper, more than $2,000 \mathrm{ppm}$ of nitrite was formed by the incubation of komatsuna juice alone at $30^{\circ} \mathrm{C}$ for $24 \mathrm{hr}$. In this case, nitrate-reducing microorganisms exsisting originally in komatsuna seemed to be responsible to the formation of nitrite. Such a high accumulation of nitrite may be due to the following reasons: (a) komatsuna has high content of nitrate amounting to over $5,000 \mathrm{ppm}$, and (b) nitrate-accumulating ability of microorganisms in komatsuna seems to be stronger than that of $B$. natto in natto.

It is unlikely that vegetable juice is stored at $30^{\circ} \mathrm{C}$ for $24 \mathrm{hr}$ in our daily life, but foods are often stood for an unnecessarily long time. Thus, in fact, it may happen that a significant amount of nitrite is formed by the action of nitrate-reducing microorganisms and nitrate, which are present in most vegetables, on standing, and that the nitrite accumulated is further reacted with secondary amines in other foods to form carcinogenic nitroso compounds in stomach.

From the standpoint of food hygiene, there are many reports related to the formation of nitroso compounds in vitro and in vivo by mixing of nitrite or nitrate and secondary or tertiary amines, and it has been pointed out that nitrosocompounds should be formed by the combination of different kinds of foods, such as vegetables as a source of nitrite and fishes as a source of secondary amines. ${ }^{5), 9), 21) 244}$ The results shown in Table 2 and 3 support the above indication.

Inoue $^{\text {r) }}$ and Ishiwata, et $a l .{ }^{8)}$ reported that DMNA was formed in the stomach of guineapig when nitrate, DMA and nitrate-reducing bacterium were orally administered, and in these cases, the $\mathrm{pH}$ and volume of stomach contents became higher than the normal values, indicating a lowering of the stomach function by the adminstration of a large number of bacterial cells.

In the present study, the formation of DMNA in the stomach of guinea-pig was also observed when incubated komatsuna juice containing a large amount of nitrite and ika-shiokara containing DMA were administered to the animal. In this case, there was little difference in the $\mathrm{pH}$ value and volume of the stomach contents between the group administered with incubated komatsuna juice and ika-shiokara and the control groups omitted one of them or replaced incubated komatsuna juice to fresh one, showing the formation of DMNA in the normal state of stomach.

DMA examined in the present paper is one of the most hardly nitrosatable amines. Sakai, et $a l .{ }^{5)}$ observed that $5 \mathrm{mg}$ of DMNA was formed in the stomach contents of rabbits after the administration of $1,000 \mathrm{mg}$ of sodium nitrite 
and $500 \mathrm{mg}$ of DMA. HCl. Although the amount of DMNA formed in the stomach was increased with increasing the amount of sodium nitrite and $\mathrm{DMA} \cdot \mathrm{HCl}$ administered, the nitrosation of strong basic secondary amines such as DMA, diethylamine or dipropylamine was extremely slow.

On the other hand, there are many other nitrosatable compounds which are used for drugs and pesticides or exsist in nature as biological constituents. Since some of them are easily reacted with nitrite to form carcinogenic nitroso compounds in acidic medium, there is a possibility of in vivo formation of these compounds in human stomach, when the corresponding nitrosatable compounds are taken with some foods containig a large amount of nitrite, which is formed from nitrate by nitrate-reducing microorganisms present in foods.

\section{Acknowlegements}

The author is indebted to Dr. M. Ishidate, Tokyo Biochemical Institute, and Prof. T. Murata, Shizuoka College of Pharmacy, for their encouragements. This work was supported by Cancer Research Funds (1975) from the Ministry of Health and Welfare entitled "Studies on chemical carcinogens in the life environment", Scientific Research Funds (1975) from the Ministry of Education, Science and Culture, and Special Research Funds (1975) from National Institute of Hygienic Sciences, and was co-worked with Dr. A. Tanimura and Miss H. Ito, National Institute of Hygienic Sciences.

\section{References}

1) International Agency for Research on Cancer: "IARC Monographs on the Evaluation of Carcinogenic Risk of Chemicals to Man", Vol. 1, p. 95 (1972), World Health Organization.

2) Sakai, A., Tanimura, A.: J. Food Hyg. Soc., 12, 485 (1971).

3) Nakamura, M., Usuki, M.: ibid., 14, 264
(1973).

4) Panalaks, T., Iyengar, J.R., Sen, N.P.: J. Assoc. Offic. Anal. Chem., 56, 621 (1973).

5) Sakai, A., Tanimura, A.: J. Food Hyg. Soc., 12, 170 (1971).

6) Eisenbrand, G., Ungerer, O., Preussmann, R.: Fd. Cosmet. Toxicol., 12, 229 (1974).

7) Ishiwata, H., Tanimura, A., Ishidate, M.: J. Food Hyg. Soc., 17, 59 (1976).

8) Inoue, Y.: Hiroshima Daigaku Igaku Zasshi, 20, 357 (1972).

9) Ayanaba, A., Alexander, M.: Appl. Microbiol. 25, 862 (1973).

10) Harada, M., Nakamura, Y., Tanimura, A.: J. Food Hyg. Soc., 13, 36 (1972).

11) Siciliano, J., Kralick, S., Heisler. E. G., Schwartz, J.H., White, J.W.: J. Agric. Food Chem., 23, 461 (1975).

12) Kawamura, T., Sakai, K., Miyazawa, F., Wada, H., Ito, Y., Tanimura, A.: J. Food Hyg. Soc., 12, 192 (1971).

13) Ito, Y., Sakuta, H., Takada. H., Tanimura, A.: ibid., 12, 404 (1971).

14) Ministry of Health and Welfare: "The Pharmacopoeia of Japan" 7th Ed. p. 756 (1961).

15) Harada, M., Ishiwata, H., Nakamura, Y., Tanimura, A., Ishidate, M.: J. Food Hyg. Soc., 16, 11 (1975).

16) Ishiwata, H., Tanimura, A., Ishidate, M.: ibid., 16, 234 (1975).

17) Ito, Y., Sakuta, H. YokotA, S., Ayukawa, I., Tanimura, A.: ibid., 12, 185 (1971).

18) Ito, Y., Tanimura, A.: ibid., 12, 177 (1971).

19) Mirvish, S.S.: J. Natl. Cancer Inst., 44, 633 (1970).

20) Ishiwata, H.: J. Food. Hyg. Soc., 17, 369 (1976).

21) Tanimura, A.: J. Food Hyg. Soc., 12, 277 (1971).

22) Haenszel, W., Kurihara, M., Sege, M., Lee, R. K. C.: J. Nat1. Cancer Inst., 49, 969 (1972).

23) Tannenbaum, S.R., Sinskey, A.J., Weisman, M., Bishop, W.: ibid., 53, 79 (1974).

24) Sen, N.P., Smith, D.C., Schwinghamer, L.: Fd. Cosmet. Toxicol., 7, 301 (1969). 